\title{
Role of Brain Natriuretic Peptide assay in identifying children with pneumonia complicated by congestive cardiac failure \\ Sadoh $W^{*}$, Osarogiagbon WO \\ Department of Child Health, University of Benin/ University of Benin Teaching Hospital, Benin City, Edo State, Nigeria
}

*Correspondence: Professor WE Sadoh, Department of Child Health, University of Benin/ University of Benin Teaching Hospital, PMB 1111, Benin City, Edo State, Nigeria. Email: sadohehi@yahoo.com, ehidiamen.sadoh@uniben.edu; ORCID - https://orcid.org/0000-0001-7985-5164.

\begin{abstract}
Background: Pneumonia in children is a leading cause of morbidity and mortality in developing countries. It is often complicated by Congestive Cardiac Failure (CCF), with some of the symptoms similar to those of pneumonia. Brain Natriuretic Peptide (BNP) assay can differentiate cardiac from respiratory-related causes of respiratory distress.

Objective: To determine the role of BNP in differentiating isolated pneumonia from pneumonia complicated by CCF.

Methods: Over a 12-month period, consecutive children with radiologically-confirmed pneumonia were recruited for the study. Those with complicating CCF were noted. All the children had blood BNP assay done by ELISA, prior to treatment. Biodata was obtained and the children were grouped into those with isolated pneumonia and those with pneumonia complicated by CCF.

Results: Fifty children were recruited; of these 26 (52.0\%) had isolated pneumonia while 24 (48.0\%) had pneumonia with CCF. The median age of the children was 6 months. The median BNP values for the isolated pneumonia group (229.4 ng/1), was significantly lower than that of pneumonia complicated by CCF group (917.3 $\mathrm{ng} / \mathrm{l}) ;(\mathrm{p}=0.007)$. ROC showed that a BNP value $>550 \mathrm{ng} / \mathrm{l}$ could identify children with pneumonia complicated with CCF from those with isolated pneumonia with a sensitivity of $70.4 \%$ and specificity of $63.4 \%$.

Conclusion: A BNP assay prior to treatment of $>550 \mathrm{ng} / 1$ can differentiate children with pneumonia complicated with CCF from those without CCF.
\end{abstract}

Keywords: Biomarker, Childhood, Heart failure, Pneumonia, Brain Natriuretic Peptide

\section{Introduction}

Pneumonia is one of the major causes of childhood morbidity and mortality worldwide, being responsible for 151 million new cases annually, ${ }^{[1]}$ and contributing $20 \%$ of mortality in children under five years of age. ${ }^{[2]}$ In Nigeria, an estimated 177,000 children aged less than five years of age died from pneumonia in 2008. [3] Congestive cardiac failure, which is the inability of the heart to pump enough blood for tissue metabolism despite adequate filling pressures, ${ }^{[4]}$ often complicates pneumonia in childhood. [5, 6] This complication increases the mortality associated with childhood pneumonia. [7] The 
clinical features of pneumonia such as cough and respiratory difficulty are shared with congestive cardiac failure. Although there are clinical diagnostic criteria for heart failure in children (such as the Modified Ross Score [8] and the Omokhodion Heart Failure Index, [9]) the diagnostic criteria are non-specific, hence early detection of heart failure as a complication of pneumonia may be difficult.

The Brain Natriuretic Peptide (BNP) is a neurohormone secreted by the ventricles in response to volume and pressure loading. ${ }^{[10]}$ It is secreted in situations of heart failure and its blood level correlates well with the severity and prognosis of the disease. ${ }^{[11,12]}$ BNP has been shown, mostly in adult studies, to differentiate respiratory difficulty caused by heart failure from those of respiratory disease origin. ${ }^{[13]}$ A single test such as BNP assay may allow for early detection of heart failure and consequently, the institution of prompt and adequate treatment of heart failure, thereby mitigating the associated mortality.

In this study, the usefulness of BNP in identifying children with pneumonia complicated with congestive cardiac heart failure from those who have isolated pneumonia was evaluated.

\section{Method}

This was a cross-sectional study involving consecutive patients presenting to the Children's Emergency Room of a Teaching Hospital in Nigeria with pneumonia, conducted between March 2011 and February 2012. Ethical approval was given by the Ethics Committee of the University of Benin Teaching Hospital.

The diagnosis of pneumonia was confirmed on Chest radiograph showing pneumonic infiltrates in either or both lung fields. A positive and independent radiographic report of pneumonia by the radiologist and the paediatric pulmonologist was confirmatory of pneumonia.

The age, gender and socioeconomic class (SEC) of the subjects were documented. The SEC was determined using the model recommended by Olusanya et al. [14] Each patient was clinically evaluated and the outcome was recorded.

The children were evaluated for congestive cardiac failure by a Senior Registrar and the diagnosis was made when the patient fulfilled the clinical diagnostic criteria of heart failure as outlined below: [9]

- Significant tachycardia for age $(>160$ beats/min in infancy, $>140 / \mathrm{min}$ at 2 years, $>120 / \mathrm{min}$ at 4 years and $>100 /$ min above 6 years.) Where fever was present, a $10 / \mathrm{min}$ for every $1^{0} \mathrm{C}$ rise in temperature was allowed for.

- Significant tachypnoea for age $(>60$ cycles/min in the newborn, > 40 cycles/ min $<24$ months, 30 cycles/ min in $2-5$ years, $>28$ cycles/ $\mathrm{min}$ in $5-10$ years and $>25$ cycles/ $\min$ in $>10$ years)

- Cardiomegaly (displaced apex beat with a central trachea or cardiothoracic ratio $>60 \%$ in $<5$ years and $>50 \%$ in $>5$ years)

- Tender hepatomegaly of at least $3 \mathrm{~cm}$ size below the right costal margin.

The fulfilment of hepatomegaly and any other two of the four criteria above was diagnostic of CCF.

Prior to the commencement of therapy, two millilitres of blood was obtained from all the children for BNP estimation. The plasma was decanted into a universal bottle after spinning and kept in a freezer at $-4^{0}$ Centigrade prior to analysis. The BNP was measured by the Electrochemiluminescence Immunoassay method with Chemwell Microstrip reader by Awareness Technology ${ }^{\circledR}$, USA. The lower limit of measurement of the assay was $0.00 \mathrm{ng} / \mathrm{ml}$. The BNP test kit lot number was 20110513, 
manufactured by Hangzou Eastbiopharm, Hangzhou, China.

Children with congenital heart diseases, HIV/AIDS and those without BNP estimation were excluded from the study. Congenital heart disease was diagnosed by the echocardiographic screening of all the children with pneumonia, using an Aloka Prosound ${ }^{\circledR}$ SSD 4000SV. HIV was diagnosed by DNA PCR in children $<18$ months and by serology in those $>18$ months. HIV test was done for children, clinically suspected to have HIV and those of mothers with HIV seropositivity. The children with isolated pneumonia were treated with antibiotics while those with heart failure had diuretics (Frusemide ${ }^{\circledR}$ ) along with antibiotics. Digoxin was included when the signs of CCF did not resolve in 48 hours. The details of the methodology had earlier been described in previous publications. $[15,16]$

\section{Statistical analysis}

The data were entered into the spreadsheet and analysed using SPSS 16 (Chicago IL). Simple proportions were presented in percentages. The age and BNP values, because they were not normally distributed, were presented as median and range. The differences in median values were tested by median test and comparison of proportions was done with $\chi^{2}$ or Fischer's Exact Test as appropriate. The Receiver Operator's Characteristic (ROC) curve was constructed to determine the best BNP cut-off value at which children with pneumonia also had CCF. The level of significance was set at $p<0.05$.

\section{Results}

The fifty subjects comprised 26 (52.0\%) children with isolated bronchopneumonia while 24 (48.0\%) had bronchopneumonia with CCF. Of the 50 subjects, 25 (50.0\%) were males. The age ranged between one month and 48 months with a median age of 6 months. The median age (range) of the male $6(1-48)$ months was not significantly different from that of the female $5(1-42)$ months $(p=0.36)$. The gender and socioeconomic distribution of the subjects in both arms of the study are shown in Table I.

Table I: The gender and socioeconomic class distribution of the subjects

\begin{tabular}{llll}
\hline Features & $\begin{array}{l}\text { Isolated pneumonia } \\
\text { N (\%) }\end{array}$ & $\begin{array}{l}\text { Pneumonia + CCF } \\
\text { N (\%) }\end{array}$ & P-values \\
\hline Gender & $13(52.0)$ & $12(48.0)$ & 1.00 \\
Male $(\mathrm{n}=25)$ & $13(52.0)$ & $12(48.0)$ & \\
Female $(\mathrm{n}=25)$ & & $7(53.8)$ & 0.60 \\
Socioeconomic class & $6(46.2)$ & $6(37.5)$ & \\
High $(\mathrm{n}=13)$ & $10(62.5)$ & $11(52.4)$ & \\
Middle $(\mathrm{n}=16)$ & $10(47.6)$ & & \\
Low $(\mathrm{n}=21)$ & & & \\
\hline
\end{tabular}

Of the 50 subjects, six (12.0\%) died while 44 $(88.0 \%)$ were discharged. The median BNP values of the group with isolated pneumonia was $229.4 n g / 1$ (range: 4 - 1364ng/1) while the value for the group with pneumonia complicated by CCF was $917.3 \mathrm{ng} / 1$ (range: $81.8-1759 \mathrm{ng} / 1)$, $(\mathrm{p}$ value $=0.007)$.
The median value of BNP for children who died was $1121.5 \mathrm{ng} / 1$ (range: 54.5 - 1759.0ng/1) and this was higher than the value $[443.3 \mathrm{ng} / 1$ (range: 4 - 1574ng/1)] for children who survived but without statistical significance $(p$ $=$ 0.16). The Receiver Operator's Characteristics showed that at a BNP value of $550.5 \mathrm{ng} / 1$, the sensitivity and specificity were 
$70.8 \%$ and $63.4 \%$ respectively in identifying children with pneumonia complicated by CCF. The positive predictive value was $65.4 \%$ while the negative predictive value was $29.3 \%$. The area under the curve of the ROC analysis was $72.4 \%(\mathrm{CI}=58.3-86.4 \%), \mathrm{p}=0.007$. (Figure 1 )

\section{Discussion}

The median blood BNP level for children with isolated pneumonia was significantly lower than the value for children who also had CCF along with pneumonia. The higher value reflects the impact of heart failure on the elevation of blood BNP level compared to isolated pneumonia and this is consistent with the finding in a similar study conducted by $\mathrm{Hu}$ et al [17] amongst Chinese children.

The finding was also consistent with the finding in a study in which the blood level of BNP was higher among subjects in whom dyspnea was of cardiac origin rather than respiratory origin. [13] In a study evaluating the blood level of BNP among children with pneumonia complicated with CCF in China, [18] higher BNP levels were found among children with pneumonia complicated with CCF compared to those with isolated pneumonia. However, the values of BNP obtained in that study were very low compared to another Chinese study by Hu et al ${ }^{[17]}$ and the findings in the present study.

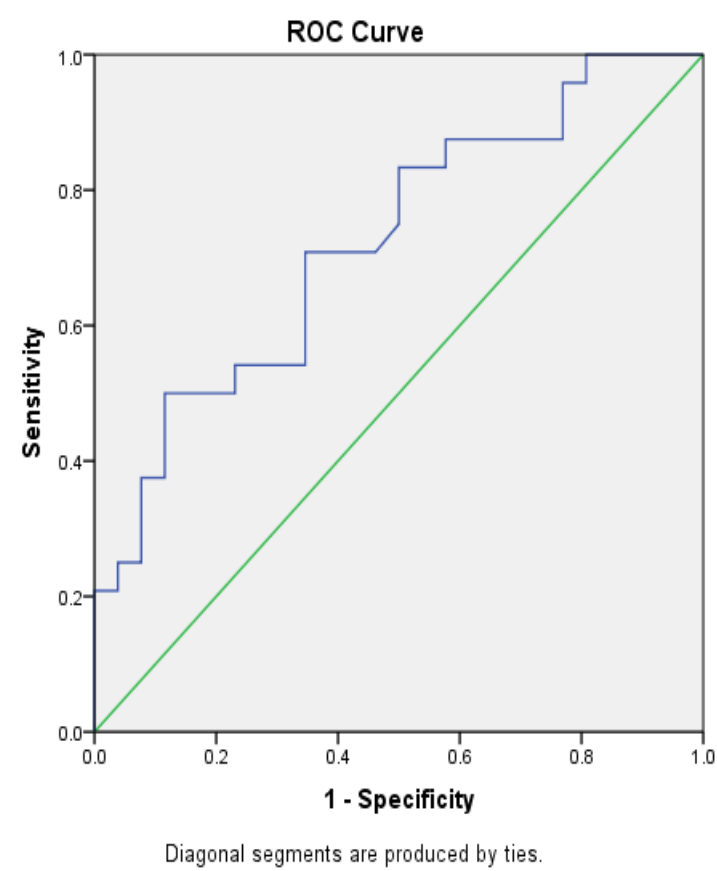

Figure 1: The ROC curve of subjects with pneumonia and those with pneumonia and CCF

The reason for the difference in blood BNP levels between the cited studies is not obvious; it may be related to the method of BNP assay rather than subject characteristics since the subjects in both studies were Chinese children. [17,18] The blood level of BNP is elevated in ventricular dysfunction [10] and as such, children with underlying congenital heart disease with ventricular dysfunction could also have elevated BNP levels in the absence of heart failure. This potential bias caused by undiagnosed structural heart disease was eliminated with the performance of transthoracic echocardiography for all the children in the present study. The blood level of BNP among children with isolated pneumonia was higher than the normal value of $100 \mathrm{ng} / \mathrm{ml}$. [19] This finding suggests that 
elevated blood level of BNP also occurs in pneumonia and this is in consonance with a previous study. [19]

The ROC analysis determined that a BNP level of $550 \mathrm{ng} / 1$ is the best cut off value above which pneumonia complicated with CCF can be diagnosed seven of ten times when they coexist and over six of ten times when they do not coexist. The sensitivity and specificity values of $70 \%$ and $63.0 \%$ respectively in this study are lower than those obtained from an earlier study, [18] in which both values were higher than $80 \%$. The reason for the observed difference is unclear but it may be related to biologic characteristics of the subjects. It is worthy of note that the negative predictive value obtained in this study is low compared to the finding in a previous study and is a limitation to its clinical applicability as it could increase the number of false positive cases of pneumonia complicated by CCF.

In this study, children who died had higher blood BNP levels compared to those who survived. This finding suggests worse severity of the disease among the casualties compared to the survivors. Indeed, BNP levels have been shown to be highly positively correlated with the severity of CCF. [11] A relatively higher blood BNP level value of over $1000 \mathrm{ng} / \mathrm{ml}$, as observed in the median BNP values in the children who died in the present study, may be a marker or risk factor for mortality. It is, thus, an indication for a more aggressive treatment and closer monitoring of such children. This aspect of the application of BNP levels will require further studies.

The sources of bias such as age and gender which are known to affect BNP level [20] were controlled for in this study. The median ages of both sexes and the gender distribution of the subjects in this study were similar.

\section{Conclusion}

Significantly higher BNP levels occur among children with pneumonia complicated by CCF compared to children with isolated pneumonia. A single BNP assay prior to treatment with values $>550 \mathrm{ng} / 1$ may indicate the presence of CCF in a child with pneumonia and very high value (1000ng/l) could be a risk factor for mortality.

Authors' Contribution: The conception and design, data collection, analysis and interpretation, manuscript writing and approval of the final draft were all done by both authors.

Conflict of interest: None declared.

Funding: Self-funded.

Publication History: Submitted 03 October 2018; Revised 06 November 2018; Accepted 07 November 2018

\section{References}

1. Rudan I, Tomaskovic L, Boschi-Pinto C, Campbell H, for the WHO CHERG Reference Group. Global estimates of the incidence of clinical pneumonia among children under five years of age. Bull World Health Org 2004; 82: 895-903.

2. Bryce J, Boschi-Pinto C, Shibuya K, Black RE for the WHO CHERG. WHO estimates of the causes of death in children. Lancet 2005; 365: 1147-52.

3. Black RE, Cousens S, Johnson HL, Lawn JE, Rudan I, et al for the WHO CHERG. Global, regional and national causes of child mortality in 2008: a systematic analysis. The Lancet 2010; 375: 1969 - 87.

4. McMurray JJ, Adamopoulos S, Anker SD, Auricchio A, Böhm M, Dickstein $\mathrm{K}$, Falk V, et al. ESC Committee for practice guidelines: ESC guidelines for the diagnosis and treatment of acute and chronic heart failure 2012. The Taskforce for the diagnosis and treatment of acute and chronic heart 
failure 2012 of the European Society of Cardiology. Developed in collaboration with the Heart Failure Association (HFA) of the ESC. Eur Heart J 2012; 33: 1787-847.

5. Sadoh WE, Okperi B, Ikhurionan P, Monday P, Sadoh AE. Evaluation of predictors of mortality associated with childhood heart failure in Nigeria: a two-center study. Pediatr Emerg Care 2018. Published online Feb 52018. DOI: 10.109/PEC000000000001427 [Epub ahead of print].

6. Lagunju IA, Omokhodion SI. Childhood heart failure in Ibadan. West Afr J Med 2003; 22: 42-5.

7. Osarogiagbon WO, Sadoh WE. Outcome of pneumonia in children presenting to the University of Benin Teaching Hospital, Nigeria. South Afr Resp J 2013; 19: 117-20.

8. Ross RD, Bollinger RO, Pinsky WW. Grading the severity of congestive heart failure in infants. Pediatr Cardiol 1992; 13: 72-5.

9. Omokhodion SI, Okolo CM, Obetoh C, Abowheyere J. Proposed severity index score (SIS) scheme for childhood heart failure. Abstract of the $4^{\text {th }}$ World Congress of Heart Failure: mechanism and management; Jerusalem, Israel, May 26 - 29 1996. Abstract 763. J Cardiac Failure 1996; 3.

10. Yasue $H$, Yoshimura $M$, Sumida $H$, Kikuta K, Kugiyama K, Jougasaki M, et al. Localisation and mechanism of secretion of B-type natriuretic peptide in comparison with those of A-type natriuretic peptide in normal subjects and patients with heart failure. Circulation 1994; 90: 195-203.
11. Hunt PJ, Richards AM, Nicholls MG, Yandle TG, Doughty RN, Espiner EA. Immunoreactive amino-terminal probrain natriuretic peptides (NTproBNP); a new marker of cardiac impairment. Clin Endocrinol 1997; 47: 287-96.

12. Mair J, Friedl W, Thomas S, Puschendorf B. Natriuretic peptide in assessment of left-ventricular dysfunction. Scand J Clin Lab Invest Suppl 1999; 230: 132-42.

13. Morrison LK, Harrison BS, Krishnaswamy $\mathrm{P}$, Kasanegra $\mathrm{R}$, Clopton P, Maisel A. Utility of a rapid B-Natriuretic peptide assay in differentiating congestive heart failure from lung disease in patients presenting with dyspnea. J Am Coll Cardiol 2002; 39: 202-9.

14. Olusanya O, Okpere E, Ezimokhai M. The importance of socioeconomic class in voluntary fertility control in a developing country West Afri J Med 1985; 4: 205-12.

15. Sadoh WE, Osarogiagbon WO. Pneumonia complicated by congestive cardiac failure in Nigerian children. East African Medical Journal 2012; 89: 322-6.

16. Osarogiagbon OW, Sadoh WE. Socioeconomic and socio-demographic determinants of BNP values in children with pneumonia in Benin City. Australasian Med J 2017; 10: 4328.

17. Hu D, Liu Y, Tao H, Gao J. Clinical value of plasma B-type natriuretic peptide assay in pediatric pneumonia accompanied by heart failure. Expt Therap Med 2015; 10: 2175-9. 
18. An JD, Zhang YP, Zhou JH. Levels of serum brain natriuretic peptide in children with congestive heart failure or severe pneumonia. Zhongguo Dang Dai Er Ke Za Zhi 2006; 8: 201-4.

19. Li J, Ye H, Zhao L. B-type natriuretic peptide in predicting the severity of community acquired pneumonia. World J Emerg Med 2015; 6: 131-6.

20. Doust J, Lehman R, Glasziou P. The role of BNP testing in heart failure. Am Fam Physician 2006; 74: 1893-8. 